\title{
Non-Insulin-Dependent Diabetes Mellitus Complicated with Idiopathic Hypoparathyroidism
}

\author{
Hiroyuki Itoh, Yuzo Matsuda, Mitsuru Nishiyama, Takao Kitagawa, Tomoko Kobayashi, \\ Yutaka Nio, Satoshi Hama, Hidemi Hosogi, Tadashi Hiroi* and Kozo Hashimoto**
}

\begin{abstract}
We report a case of non-insulin-dependent diabetes mellitus (NIDDM) complicated with idiopathic hypoparathyroidism. A 74-year-old male was hospitalized because of diplopia. He was revealed to have NIDDM. The levels of serum Ca and intact-PTH were $6.3 \mathrm{mg} / \mathrm{dl}$ and $<5 \mathrm{pg} / \mathrm{ml}$, respectively. Brain computed tomography revealed abnormal calcification in the cerebral basal ganglia and the cerebellum. After recovery from hypocalcemia, the endogenous insulin secretion was normalized. It is suggested that the pathogenesis of NIDDM in this patient may have been related to an insulin secretory defect as a result of hypocalcemia in addition to the hereditary risk. (Internal Medicine 34: 904-907, 1995)
\end{abstract}

Key words: hypocalcemia, insulin secretion, oculomotor nerve palsy

\section{Introduction}

Idiopathic hypoparathyroidism (IHP) is a rare disease characterized by hypocalcemia. We report a case of non-insulindependent diabetes mellitus (NIDDM) with right oculomotor nerve palsy in the natural course of IHP. The combination of IHP with insulin-dependent diabetes mellitus (IDDM) has been described to be a polyglandular autoimmune syndrome (1), but its genesis may differ from that of the combination of IHP and NIDDM. Only 4 cases of IHP and NIDDM have been reported however, no discussion of the pathogenesis was included (2-4).

In this patient, we examined the pancreatic endogenous insulin secretion using the glucagon stimulating test before and after the correction of hypocalcemia to evaluate the relationship between the pathogenesis of NIDDM and hypocalcemia due to hypoparathyroidism.

\section{Case Report}

A 74-year-old male was hospitalized in April 1993 because of diplopia and right blepharoptosis. He had a history of cataract and ophthalmological treatment. His mother and daughter had NIDDM.

On admission, his body temperature was $36.7^{\circ} \mathrm{C}$, height 162 $\mathrm{cm}$, weight $58 \mathrm{~kg}$, and body mass index $22.1 \mathrm{~kg} / \mathrm{m}^{2}$. The blood pressure was $142 / 64 \mathrm{mmHg}$, and the heart rate was regular and
$72 /$ min. Consciousness was clear. No abnormal findings for the skin, nails or hair were noted.

Neurological examinations revealed right blepharoptosis. The right eyeball deviated to the lateral side and did not readily move to the medial side. Both pupils were of normal size, but the right pupillary light reflexes were depressed. No involvement of the other cranial nerves was evident, nor was hemiparesis or pathological reflex present. The deep tendon reflexes were slightly diminished. Glove and stocking type disturbance of vibratory sensation was present in the peripheral extremities. He showed the cerebellar sign of wide-based ataxic gait and dysmetria on the finger-nose-finger test. Extrapyramidal signs were not evident. Chvostek's sign and Trousseau's sign were negative.

Urinalysis revealed glucosuria, $2.6 \mathrm{~g} / 24 \mathrm{~h}$. Electrolysis indicated hypocalcemia and hyperphosphatemia, as follows: serum Ca, $6.3 \mathrm{mg} / \mathrm{dl} ; \mathrm{Ca}^{2+}, 2.92 \mathrm{mg} / \mathrm{dl}$; corrected Ca by Payne's method, $5.9 \mathrm{mg} / \mathrm{dl}$; and $\mathrm{P}, 5.7 \mathrm{mg} / \mathrm{dl}$. The levels of urine $\mathrm{Ca}$ and $\mathrm{P}$ were $17 \mathrm{mg} / 24 \mathrm{~h}$ and $302 \mathrm{mg} / 24 \mathrm{~h}$, respectively. The level of intact parathyroid hormone (intact-PTH) was markedly low, $<5$ $\mathrm{pg} / \mathrm{ml}$. On the Ellsworth-Howard test, the excretion of phosphate into the urine was increased by $36.6 \mathrm{mg} / 2 \mathrm{~h}$ and that of cAMP was increased by $6.8 \mu \mathrm{mol} / \mathrm{h}$ following the intravenous administration of $\mathrm{hPTH}$. The daily profile of blood glucose levels was as follows: before breakfast, $144 \mathrm{mg} / \mathrm{dl}$; after breakfast, $265 \mathrm{mg} / \mathrm{dl}$; and before dinner, $176 \mathrm{mg} / \mathrm{dl}$. The level

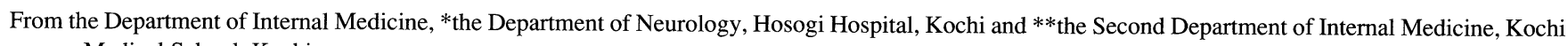
Medical School, Kochi

Received for publication January 26, 1995; Accepted for publication June 5, 1995

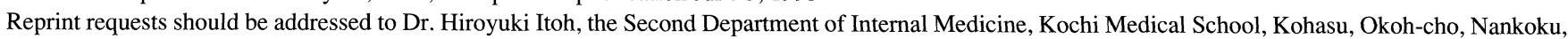
Kochi 783 
of $\mathrm{HbA}_{1 \mathrm{C}}$ was $8.7 \%$. The oral glucose tolerance test (OGTT) disclosed a blood glucose level of $137 \mathrm{mg} / \mathrm{dl}$ at the baseline, 175 $\mathrm{mg} / \mathrm{dl}$ at 30 minutes, $263 \mathrm{mg} / \mathrm{dl}$ at one hour, and $323 \mathrm{mg} / \mathrm{dl}$ at two hours. The response of IRI to the OGTT was hypoactive;

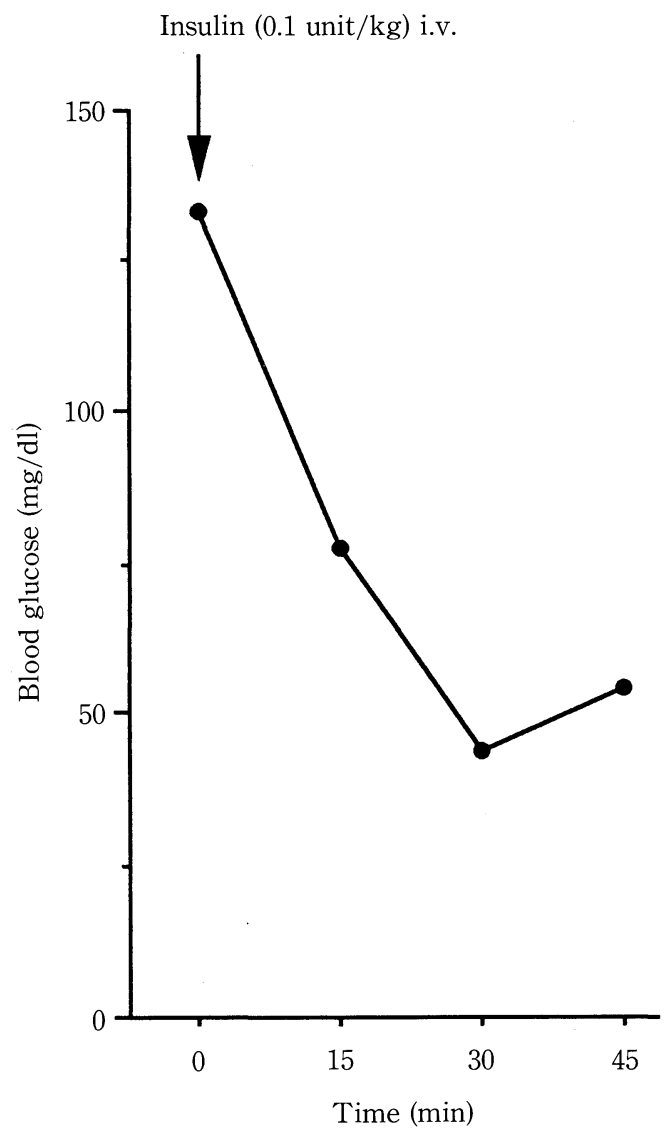

Figure 1. The patient showed hypoglycemia after intravenous administration of regular insulin.
$4.5 \mu \mathrm{U} / \mathrm{ml}$ at the baseline, $7.6 \mu \mathrm{U} / \mathrm{ml}$ at 30 minutes, $12.8 \mu \mathrm{U} / \mathrm{ml}$ at one hour, and $18.8 \mu \mathrm{U} / \mathrm{ml}$ at two hours. He showed no diabetic retinopathy on the ophthalmologic examination, but microalbuminuria ( $79.6 \mathrm{mg} / \mathrm{g} / \mathrm{creatinine})$ and mild neuropathy were noted. After the intravenous administration of regular insulin, the blood glucose level was $44 \mathrm{mg} / \mathrm{dl}$ at 30 minutes and $54 \mathrm{mg} / \mathrm{dl}$ at 45 minutes (Fig. 1); he then complained of hypoglycemic symptoms. Electrocardiography revealed a normal QT time. X-ray of the skull and computed tomography scan of the brain revealed broad and abnormal calcification in the cerebral basal ganglia and the cerebellum (Fig. 2). No ischemia of the brain was demonstrated by magnetic resonance imaging nor cerebral aneurysm by magnetic resonance angiography.

According to these findings, NIDDM with right oculomotor nerve palsy complicated with IHP was diagnosed. After 1,600kilocalorie daily diet therapy for NIDDM was initiated, the levels of blood glucose became normalized. Diplopia and blepharoptosis due to right oculomotor nerve palsy disappeared two months later. Then, administration of alfacalcidol (activated vitamin $\mathrm{D}_{3}$ ) for hypocalcemia was started, and the levels of serum Ca were elevated to $7.8 \mathrm{mg} / \mathrm{dl}$. The glucagon stimulating test was performed before and after administration of activated vitamin $\mathrm{D}_{3}$ (Fig. 3). The levels of serum C-peptide (CPR) and IRI after the administration of glucagon were significantly elevated after vitamin $\mathrm{D}_{3}$ therapy compared with those before therapy. The peak level of CPR before the correction of hypocalcemia was $5.2 \mathrm{ng} / \mathrm{ml}$ at six minutes; after the correction this CPR value increased to $7.8 \mathrm{ng} / \mathrm{ml}$ (Fig. 4).

\section{Discussion}

The time of IHP onset in this patient is unknown, but he was considered to have long-standing hypocalcemia before the onset of NIDDM due to the presence of the abnormal intracranial calcification. The combination of IHP and IDDM was described in 1980 by Neufeld et al as polyglandular autoimmune
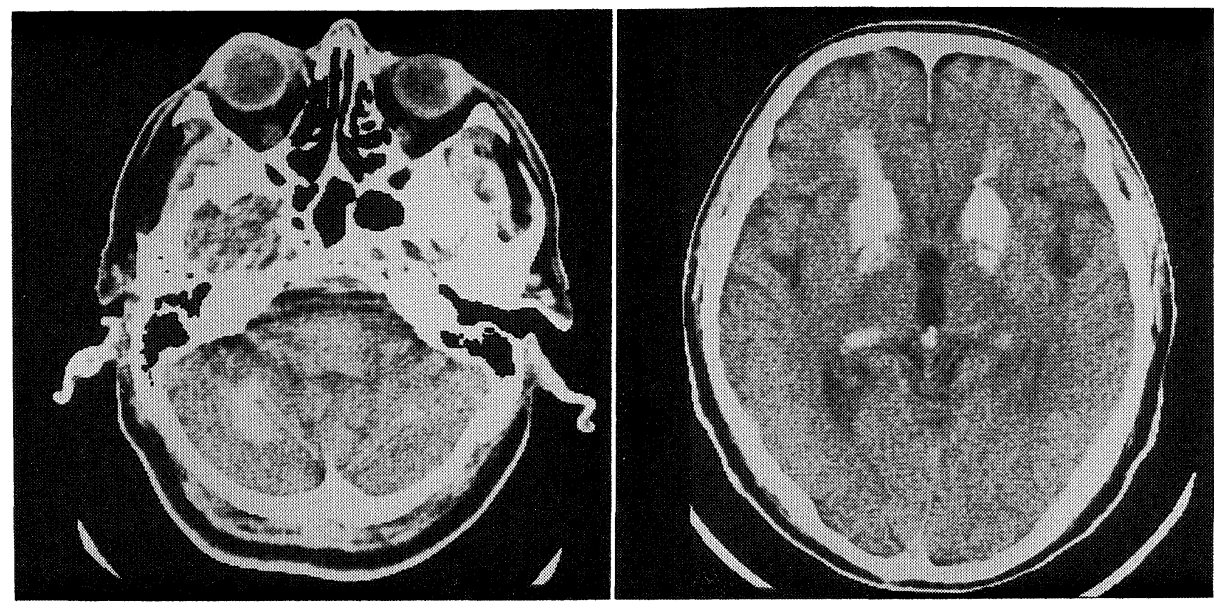

Figure 2. Brain computed tomography scan revealed abnormal calcification in the cerebral basal ganglia and the cerebellum. 
Iтон et al

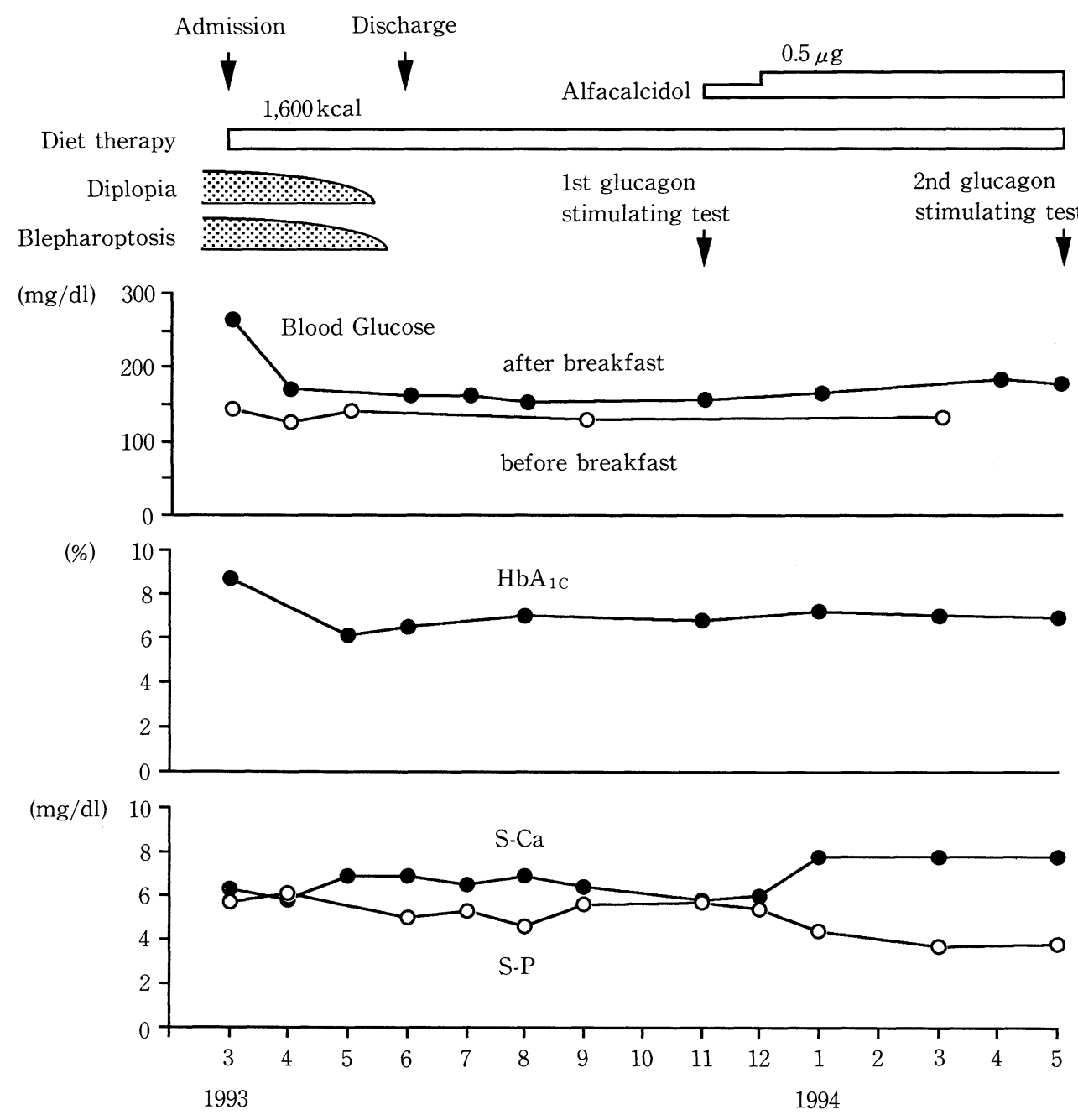

Figure 3. Clinical course of the patient.
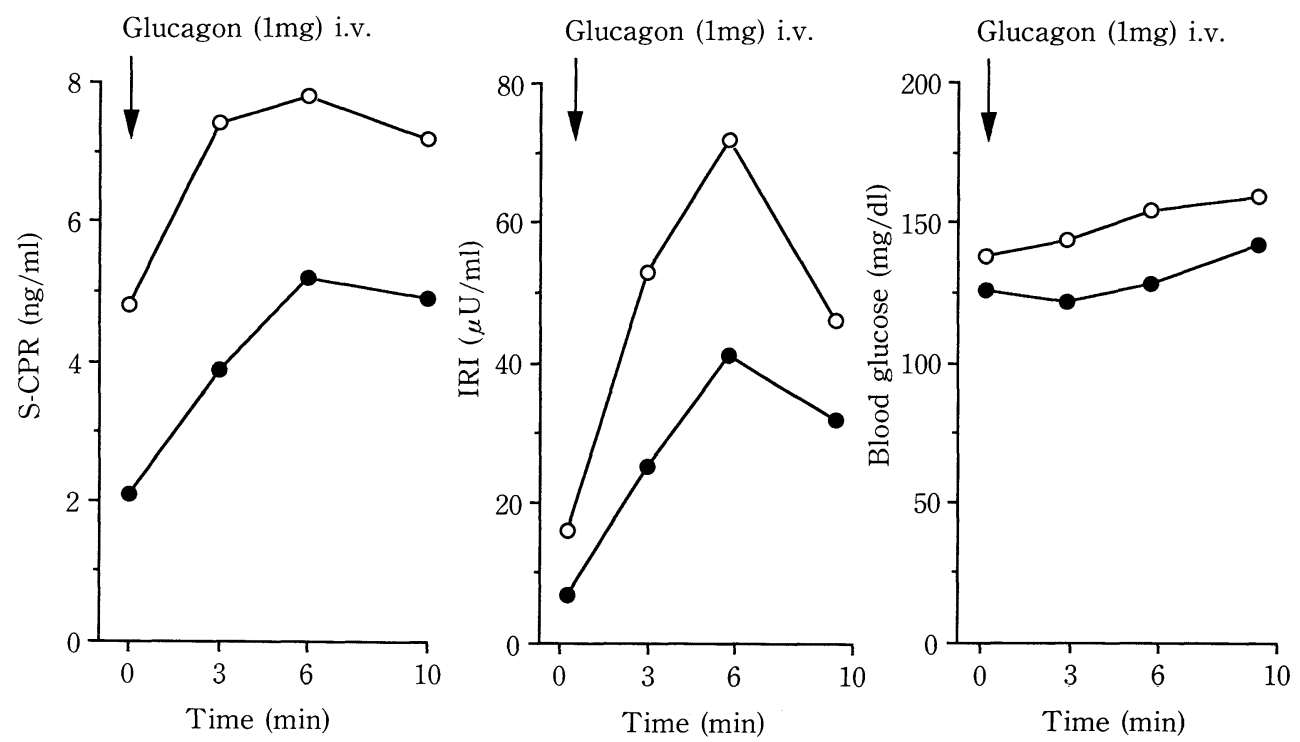

Figure 4. The glucagon stimulating test demonstrated improvement of insulin secretion after recovery from hypocalcemia (open circles) compared to that before the administration of activated vitamin $D_{3}$ (closed circles). The levels of blood glucose had no changes before and after. 
syndrome type 1 (1). This syndrome is frequently characterized by systemic endocrinopathy related to autoimmune antibodies. However, the genesis of the combination of IHP and NIDDM may differ from that of polyglandular autoimmune syndrome, but only 4 cases have been reported previously (2-4).

Here, the results of the glucagon stimulating test prior to vitamin $D_{3}$ therapy, which may reflect endogenous insulin secretion from pancreatic $\beta$-cells, suggested that the hyperglycemia in this patient was at least partially due to an insulin secretory defect. Peripheral insulin resistance was not likely because of the occurrence of a hypoglycemic episode after the intravenous administration of regular insulin, though we did not examine the insulin sensitivity quantitatively by the glucose clamp or the steady state plasma glucose level method.

It has been confirmed that the insulin secretion from the pancreas is disturbed in the absence of extracellular $\mathrm{Ca}^{2+}$ in vitro $(5,6)$. The mechanism of the insulin secretion from pancreatic $\beta$-cells has been described, and it was confirmed that the entry of extracellular $\mathrm{Ca}^{2+}$ into the intracellular space via the voltage-dependent $\mathrm{Ca}^{2+}$ channel is an important step in the process of insulin release $(7,8)$. Yasuda et al (5) and Ikeda et al (9) reported that insulin response during the OGTT was reduced significantly in patients with IHP without diabetes mellitus compared to those of normal subjects and the response improved after recovery from hypocalcemia.

In the present patient the insulin secretion during the glucagon stimulating test was normalized in parallel with the correction of hypocalcemia following the administration of activated vitamin $\mathrm{D}_{3}$, although we did not evaluate follow-up OGTT or urine CPR. Improvement of insulin secretion due to blood glucose control was not considered likely because the glucagon stimulating test was performed after the levels of blood glucose became stable by diet therapy. Thus, we suggest that the pathogenesis of NIDDM was related to an insulin secretory defect as a result of hypocalcemia due to hypoparathyroidism, in addition to hereditary risk of NIDDM. One case of other four patients with IHP and NIDDM had a strong hereditary risk for NIDDM as well (4).

However, it was reported that the vitamin $D_{3}$ receptor is localized in pancreatic $\beta$-cells and vitamin $\mathrm{D}_{3}$ might affect insulin secretion (10). Thus, the levels of $1,25-(\mathrm{OH})_{2} \mathrm{D}$ concentration should have been measured before and after administration of alfacalcidol.

It is obvious that NIDDM is not a single disorder but rather a syndrome with wide heterogeneity. This patient was not obese and was elderly at onset. In the elderly, the level of serum calcium tends to be depressed. It is also reported that most nonobese and elderly diabetic patients show an insulin secretory defect (11). Therefore, we propose the recognition of hypocalcemia to be one of the pathogenetic mechanisms of NIDDM.

It was reported that palsies of the extraocular muscle nerves are seen in $0.7-2 \%$ of diabetic patients and that the oculomotor nerve is most frequently involved $(12,13)$. Satisfactory recovery of nerve function is generally observed within several months after the control of blood glucose. In the present patient, diplopia and blepharoptosis disappeared and the mobility of the right eyeball was normalized within two months after admission. There has been no report to our knowledge of oculomotor nerve palsy complicated with IHP. Thus, the right oculomotor nerve palsy in the present patient was thought to be a mononeuropathy caused by diabetes.

\section{References}

1) Neufeld M, Maclaren N, Blizzard R. Autoimmune polyglandular syndrome. Pediatr Ann 9: 154, 1980.

2) Shigemasa C, Tanaka T, Yoshida A, Okamura Y, Mashiba H, Abe K. A case of idiopathic hypoparathyroidism showed improvement of hypocalcemia and insulin secretion with administration of $1 \alpha$ hydroxycholecalciferol. Naika 47: 327, 1981 (in Japanese).

3) Akasu F, Haraguchi K, Tsunoda S, Shiozawa Z, Onaya T. Hypoparathyroidism associated with ossification of posterior longitudinal ligament of the spine (OPLL) and glucose intolerance - report of two cases. Naika 57: 383, 1986 (in Japanese).

4) Takeda $H$, Miyano R, Machimura $H$, et al. An autopsy case of idiopathic hypoparathyroidism with diabetes mellitus. Hormone To Rinsho 39: 617, 1991 (in Japanese).

5) Yasuda K, Hurukawa Y, Okuyama M, Kikuchi M, Yoshinaga K. Glucose tolerance and insulin secretion in patients with parathyroid disorders. $\mathrm{N}$ Engl J Med 292: 501, 1975.

6) Hellman B. The significance of calcium for glucose stimulation of insulin release. Endocrinology 97: 392, 1975.

7) Bergsten $P$, Hellman $B$. Glucose inhibits insulin release when not promoting the entry of calcium into the $\beta$-cells. Biochem Biophys Res Commun 125: 875, 1984.

8) Bergsten P, Grapengiesser E, Gylfe E, Tengholm A, Hellman B. Synchronous oscillations of cytoplasmic $\mathrm{Ca}^{2+}$ and insulin release in glucosestimulated pancreatic islets. J Biol Chem 269: 8749, 1994.

9) Ikeda T, Kurahashi A, Shigemasa C, et al. Insulin and glucagon secretion in a case of idiopathic hypoparathyroidism. J Jpn Diabetes Soc 24: 581, 1981 (Abstract in English).

10) Johnson JA, Grandle JP, Roche PC, Kumar R. Immunohistochemical localization of the $1,25(\mathrm{OH})_{2} \mathrm{D}_{3}$ receptor and calbindin $\mathrm{D} 28 \mathrm{k}$ in human and rat pancreas. Am J Physiol 267: E356, 1994.

11) Arner P, Pollare T, Lithell H. Different aetiologies of type 2 (non-insulindependent) diabetes mellitus in obese and non-obese subjects. Diabetologia 34: 483, 1991.

12) Katsui Y, Takahashi A, Takezawa H. Diabetic ophthalmoplegia. An analysis of 151 clinical cases in Japan and reevaluation of the foreign three postmortem studies. Sinkei Naika 23: 122, 1985 (in Japanese).

13) Amenomori M, Yasuda $H$, Kikkawa R, Shigeta $Y$. Clinical features of diabetic mononeuropathy after rapid glycemic control. J Jpn Diabetes Soc 36: 293, 1993 (Abstract in English). 